\title{
HOW HOME-BASED TELEWORKING DURING COVID-19 PANDEMIC AFFECTS EMPLOYEE'S STRESS AND JOB PERFORMANCE
}

\author{
Alifia Daariy \\ Universitas Mercu Buana, Jakarta \\ Email: 55120120101@student.mercubuana.ac.id \\ Setyo Riyanto \\ Universitas Mercu Buana, Jakarta \\ Email: setyo.riyanto@.mercubuana.ac.id
}

\begin{abstract}
Due to societal distancing norms and nationwide lockdowns, the COVID-19 pandemic has inevitably resulted in increased use of new technology, and most institutions are shifting to homebased telework [or work from home (WFH)]. The downside of working from home has been described as a high level of job stress, which significantly affects employee mental well-being. This essay explains how home-based teleworking during a pandemic affects work-related stress and, further, employee job performance. A literature review revealed that job overload and organizational discomfort have a negative impact on employee anxiety. Meanwhile, as the barrier between personal and work lives was lifted during the pandemic, workers were unable to contribute constructively to the job. On that account, it is critical to establish distinctions between working from home and personal life. Proper training is needed if work from home is to become a feasible working option or the current norm.
\end{abstract}

Keywords: pandemic, teleworking, work from home, stress, job performance.

Received: 18 June 2021 ;

Accepted: 6 July 2021 ;

Publish; December 2021.

\section{How to Cite:}

Daariy, A., Riyanto, S. (2021). How Home-Based Teleworking During Covid-19 Pandemic Affects Employee's Stress and Job Performance. International Journal of Human Capital Management, 5 (2), 1-10. https://doi.org/10.21009/IJHCM.05.02.1 


\section{INTRODUCTION}

Although globalization and technological advances have aided economic expansion, the by-products like cut-throat competitiveness, increased workload, extreme workplace pressures, and increasing task expectations cannot be overlooked, as they all contribute greatly to occupational stress.

Occupational stress, also known as job stress, is the strain that an individual faces due to work-related conditions. Furthermore, community, culture, and lifestyle changes affect job performance and disrupt the work-life balance (Kumar et al., 2021). Work-related stress can cause hypertension, diabetes, insomnia, asthma, musculoskeletal conditions, and other health problems (Padma et al., 2015). This effect of job stress could be seen in all cultures, occupations, employee groups, households, and society in general.

The new coronavirus has exacerbated these negative consequences. It has a major impact on the global economy, impacting various markets and businesses, including tourism and airlines. Authorities have been required to make decisions such as closing borders and non-essential shops, canceling social, academic, and sporting events where a large number of people are expected to participate, maintaining a general or municipal quarantine, and physically separating and isolating vulnerable persons (Benton et al., 2021; Madero et al., 2020). These have the function of isolating individuals by using containment as one of the most effective prevention methods.

The pandemic has forced office workers to work from home, while the government forbids any operation involving many people congregating in one place. Except for people employed in medicine, journalism, and basic commodities, remote working has become the 'new standard' for many companies (Kumar et al., 2021). The consequences of the COVID-19 pandemic on remote job methods to reduce the number of infections while having a significant impact on the economy and various industry sectors (Madero et al., 2020).

Though this method of working has lots of benefits indeed, teleworking is posing additional problems for workers who have begun to experience anxiety, technostress due to digitalization and loss of social contact, dissatisfaction, workplace pressure, counterproductive work activity, fatigue, burnout, depersonalization, and increased turnover intention (Nemteanu \& Dabija, 2021).

In line with previous outbreak findings (SARS, equine influenza, Ebola) and other reports (in Kumar et al., 2021), the current studies conducted in China and Italy have also confirmed that people have been suffering from severe mental health problems as a result of the COVID-19 epidemic (Mazza et al., 2020; Wang et al., 2020).

In the light of the COVID-19 pandemic, organizations must sustain an adequate degree of worker satisfaction during the COVID-19 pandemic, increasing employee morale. That said, human resource managers need to implement processes and job policies that will keep employees motivated (Nemteanu \& Dabija, 2021).

This article plans to describe the impact of home-based teleworking with COVID-19induced stressors on employee anxiety and, further, work performance. The paper is structured as follows: the following literature consists of literature on home-based teleworking, occupational stress, and COVID-19 related stressors. The next section discusses the approach used in the study, followed by a discussion and findings compared with current evidence from the literature, and finally, the conclusion.

\section{LITERATURE REVIEW}

\section{Home-based teleworking}

The future of work has been identified as one of the latest transformative developments since it includes networking, innovative strategies for talent management, and changing working tools. As a result, it affects the role of human resources in businesses (Madero et al., 2020). 
For various causes, more organizations and people are gradually feeling the need to operate from home or away from the conventional workplace. Given the growing growth and evolution of technology, the new work mode known as teleworking has adequately met this need in recent times (De' et al., 2020; Uford, 2021).

These developments have resulted in the use of a variety of technology and digital resources to carry out routine activities such as attending and/or coordinating meetings by video conferencing, working with team members on task completion, reports and/or presentations preparation, electronic registers use, etc. (Nemteanu \& Dabija, 2021).

Telecommuting or teleworking is a work arrangement in which individuals undertake duties - that would ordinarily be performed at a major or main workplace - somewhere else for at least parts of their work schedule, utilizing electronic media to engage with individuals inside and outside the firm (Gajendran \& Harrison, 2007). Eurofound and ILO (International Labour Organization) defined teleworking, in ILO (2020), as the "usage of digital and communication technology (ICTs), such as smartphones, tablets, notebooks, and desktop computers, for work done beyond the employee's premises." In other words, telework refers to "work accomplished by the use of ICTs and performed outside of the employer's locations."

Kurland and Bailey (1999) wrote that teleworking frequently serves as a shift from on-site supervision to remote management, from face-to-face contact to virtual interaction, from on-site working to off-site or multiple-site working, and, in the context of teams side-by-side participation to virtual teamwork.

In a guide published by ILO (2020a), telecommuting, teleworking, and working from home are frequently used interchangeably to refer to new and growing modes of working outside the main firm or workplace of the employee. There may be minor distinctions between these terms. Telecommuting is the use of telecommunications to replace commuter travel. The distinctions between the phrases "teleworking" and "telecommuting" mostly because telework is wider and may not necessarily substitute for commuting, although they are minor.

WFH, a work arrangement in which a person performs the basic functions of his or her profession while remaining at home and utilizing information and communication technologies (ICT), is classified as home-based telework. The distinction is that teleworking may occur in locations other than the main workstation or the employee's facilities (ILO, 2020a). Nowadays, telework is broadly defined as any sort of dispersed work made possible by using information and communication technologies (ICTs) (Loia \& Adinolfi, 2021).

As Aguilera, Lethiais, Rallet, and Proulhac (2016) stated, home-based teleworking is uncommon and reserved only for a few intellectual practitioners who need a high level of job autonomy and have few opportunities for advancement. The economic and occupational structure of the community; the portion of employment amenable to teleworking; access to wireless internet; and possession of a personal computer are all factors that have been identified as determining the viability of working from home (Hatayama et al., 2020; ILO, 2020b).

\section{Benefits and pitfalls of teleworking}

Home-based telework has two points of view. Others say they can spend more time with their family because working at home allows them more flexibility and reduces travel time due to individual characteristics or home and family situations (Baruch, 2000; Kumar et al., 2021). Another belief is that workforce morale declines, working hours increase, it becomes difficult to balance work and family life, and job output suffers in some situations. Thus, this working method has a negative as well as a positive hand (Kumar et al., 2021).

Teleworking offers intriguing advantages to both the company and the employee. It is commonly believed that teleworking allows for better integration of family life and work through more flexible planning of job-related responsibilities and that teleworkers might feel more fulfilled than office-based workers (Baruch, 2000; Dima et al., 2019; Fonner \& Roloff, 2010; Illegems et al., 2001). It also has the potential to lower an organization's overhead costs and maximize staffing 
flexibility. In addition, home-based telework reduces transit costs and duration and allows employees to have more flexible working hours and more leisure time, and increased well-being (Gibbs et al., 2021).

While it sure has its advantages, telework also has its pitfalls. Implementing remote work may have a negative social impact by increasing social isolation. As a result, perceived work productivity and job satisfaction may suffer. Some of the other drawbacks that teleworkers face include presenteeism, a shortage of guidance, job advancement, boundary-blurring, and so on (Loia \& Adinolfi, 2021; Uford, 2021).

Illegems and his partners (2001) also wrote that this work arrangement might provide various economic benefits by raising productivity, expanding the organization's recruitment potential, and boosting the beneficial effect on the company's reputation. On the other hand, negative factors about the adoption of teleworking in terms of productivity have developed, such as higher work hours for teleworkers, fewer loyal personnel, and inadequate internal data security. Moreover, teleworking can be harmful to one's health. Somatic complaints, stress, emotional tiredness, cholesterol rises, gastrointestinal issues, and cardiovascular disease might negatively impact occupational health.

Crosbie and Moore (in Kumar et al., 2021) mentioned that due to household duties and official work, it becomes difficult for a few working professionals, especially females, to handle the WFH. Family members have been working or learning from home has exacerbated the family work dispute in the current situation. As a result, balancing employment and family life at the same time has been extremely difficult. Work has an impact on family, and family has an impact on work. Dissatisfaction, job pressures, exhaustion, and fatigue have all emerged due to distractions and inadequate time to fulfill work and family duties.

\section{COVID-19 induced occupational distress}

Occupational (business, career, or workplace) tension is one of the most serious health problems in the industrialized world since it happens in every job and is more prevalent than it was decades ago. The world of work, in particular, varies significantly from the working climate of 30 years ago: longer hours at work are not uncommon, constant shifts in culture and hierarchy are often cited, as is the lack of lifelong career paths, many of which contribute to increased presence and levels of stress (Padma et al., 2015).

As Colligan and Higgins stated (in Kumar et al., 2021), when an employee's expectations/demands do not equal the available tools, i.e., expertise, ability, or skills, they appear to feel tension. Job stress arises from both workplace and employee causes, but workplace characteristics are likely to play the most important part. They described job stress as the negative physical and emotional reactions that arise when the job requirements do not meet the worker's skills, resources, or needs. It will wreak havoc on one's health and even cause injuries (Padma et al., 2015).

Before the pandemic, WFH was a perk provided by corporations and large business houses because it allows for independence and discretion; however, it has now become the modern standard. Much of the professionals were unfamiliar with the overnight shift to WFH. Thus, a number of stressors have emerged, potentially disrupting their work results, causing anxiety, and decreasing life satisfaction (Gautam \& Sharma, 2020).

The versatility of WFH usually provides the feeling that the employee has saved time on commuting and can thereby devote the saved time to do more work. It is also of the opinion that work hours can conveniently be extended since the employee is at home. Hence, regular working hours will be increased. Those factors have been merged to create a new COVID-19 job stressor, task overload. Therefore, it is described as the feeling of having so many work-role tasks and not enough time to complete them. It calculates the extent to which job requirements outweigh staff and workplace capabilities. 
Work from home during pandemic times has caused cross-role disruptions and daily commotions, escalating the difficulty of satisfying the job and family demands. Maintaining a separation between work and non-work itself has been difficult, let alone working from home in the midst of the COVID-19 for an individual with little resources and little assistance. This discomfort has demotivated people, often resulting in missed deadlines, causing additional pain and/or anxiety (Kumar et al., 2021).

Home-based teleworking is not ideal for all organizations. Some organizations have no definite procedure, and workers must operate in the same way as in the office. Even many professionals would face challenges in terms of adequate access, dedicated personal space, time management, extra household roles, inadequate feedback, and no peer contact due to this (Baruch, 2000; Kumar et al., 2021; Vyas \& Butakhieo, 2020). Kumar et al. (2021) hypothesized that both task overload and organizational complexity increase distress and negatively impact job performance.

\section{Teleworking during pandemic}

Teleworking is not a novel concept, although it has been done to some degree in the past. However, it has now become the preferred mode of transportation for many companies, especially those in the service industry, which must adhere to physical distancing norms and restrict employee traffic. Recent advancements in emerging media and remote connectivity have greatly favored this (Kumar et al., 2021).

Employees perceive the social changes and behaviors caused by the pandemic differently: to some, they appear beneficial, allowing them to spend more time with their families and easily manage their household activities; to others, exposure to online communication technology, increased mobile device use, learning of new procedures, and the need of online platforms appear detrimental (Uford, 2021).

The WFH has been studied as a phenomenon over the last decade. Still, owing to the ongoing pandemic, it has become an alternate technique for most institutions (Kumar et al., 2021), both globally and regionally. A home office is currently a technique that entails drastic improvements in working methods, resulting in a sequence of thoughts and learning in the short and long term due to the influence of COVID-19. According to Mercer's projections (in Madero et al., 2020), job operations are likely to continue to be carried out remotely in the coming months.

Corporate has also seen telecommuting as an important lever for the continuity of its operations in near-normal circumstances. Nonetheless, teleworking presents significant problems due to a lack of face-to-face social contact, tension, and employee frustration, both of which have a negative impact on their mental health (Nemteanu \& Dabija, 2021).

A few studies showed that professionals have been working very hard to balance job and home responsibilities while still dealing with economic instability during the pandemic. This is likely to affect their personal and professional lives, causing anxiety and depression (Kumar et al., 2021; Madero Gómez et al., 2020; Mazza et al., 2020; Nemteanu \& Dabija, 2021; Riccobono, 2020; Thorstensson, 2020; Uford, 2021; Vyas \& Butakhieo, 2020), and further impact their job performance (Gibbs et al., 2021; Kumar et al., 2021).

The essay investigates two independent job stressors, including task overload and organizational distress. These stressors were regressed on anxiety and work results in order to assess the aggregate effect on life satisfaction during the COVID-19 pandemic.

\section{METHODOLOGY}

The article is distinguished by its non-experimental, plain descriptive nature, which uses a literature review to describe and perceive the characteristics inherent in the phenomena of homebased teleworking during the COVID-19 pandemic and its impact on employee anxiety and stress, and further job performance, without determining relationships among variables. 


\section{RESULT AND DISCUSSION}

Previous findings indicated that most of the employees have longer working hours, including professionals (Hegele \& Singh, 2020; Riccobono, 2020; Tavares, Santos, Diogo, \& Ratten, 2020), and some of them even have to work on weekends (Hegele \& Singh, 2020). The same thing was shown in a study done by Gibbs et al. (2021) — if work and commuting time to the office are added up and is compared to work times during WFH, the result shows employees spend around a third of an hour more time at work during WFH than during working from the office.

Moreover, individuals believe that they perform more work at this point of teleworking than they did traditionally at the organization's actual workplace. Furthermore, Tavares et al. (2020) addressed that to achieve teleworking during regular working hours, it is critical to preserve attention, concentration, and time or hour management so that there is no need to pay for losses outside of working hours and even on weekends.

\section{Home-based teleworking has a negative impact on employee's mental wellbeing}

The pandemic has led to the transition from a physical work environment to a work-fromhome environment. This big change and the widespread pandemic will cause psychological distress and affect employee work performance (Kumar et al., 2021). As per a new World Health Organization (WHO) survey, the COVID-19 pandemic has delayed or interrupted essential mental health services in 93 percent of nations globally, while demand for mental health is growing (WHO, 2020). This was also confirmed by the latest survey of UK healthcare staff, which revealed that women face anxiety and workplace disruption due to the COVID-19 pandemic (IPPR, 2020).

Uford (2021) reported the same thing: there is an important relationship between daily home-based teleworking and employees' tension during the pandemic. As work is being increasingly disassociated from conventional office space and office buildings, it must be performed in more suitable or comfortable locations free of stress. Thus, productivity will improve.

With telecommuting during self-quarantine, plus a heavy workload and an unsupportive house environment, workers may find it difficult to have a supportive working space, contributing to occupational tension. The job environment at home becomes more unpleasant as the tension level rises, and the employee will try harder to avoid it. Office employees had no choice but to deal with the burden or face having their job taken away by the organization.

Kumar et al. (2021) discovered that most participants feel nervous some of the time and much to half of the time during the lockdown. This may be attributed to the discomfort they have been experiencing due to the telework strain and handling domestic duties. More than half of people said they will consider organizational safety measures to be practiced at their workplaces until it is fully operational.

It has been found that $68 \%$ of professionals feel worn out during work from home than they did when working from an office (Riccobono, 2020). According to one study conducted in Delhi (2021), professionals who have been married and have raised workloads due to COVID-19 are at a high risk of distress. These observational findings are consistent with the findings of previous studies in which researchers claimed that when a person actively engages in one role, he is overwhelmed by the thoughts and demands of the other role, which can increase distress levels.

Based on a comparative document analysis conducted by Thorstensson (2020), employee work-life balance is further disrupted since they cannot get domestic assistance services from cleaners, babysitters, and caretakers because of the physical distancing practice. They must perform housework responsibilities and care for their family while working, resulting in poor productivity levels. Trying to complete work while surrounded by gleeful young children racing around the house is a situation many teleworkers can relate to (Kumar et al., 2021).

Tavares et al. (2020) reported that household responsibilities, caring for younger ones, and social networks are three things that often distract people when they are teleworking. Taking Kumar and partners' (2021) role hypothesis into account, it is true that balancing family and job 
obligations, particularly with an increased workload, becomes extremely difficult for an employee to handle. The researchers also agree that the inability to achieve goals causes demotivation and anxiety.

The stress-inducing chain isn't over yet, as worrying over the pandemic also has a bad impact on employees' mentality and daily lives. The fear of being infected by the virus from the outside, boredom from the inside, social isolation, and an unpredictable future supply and health care conditions impacted employees' productivity and psychological work environment (Thorstensson, 2020).

When a person's job demands more of them, they have little time for themselves, resulting in high levels of depression and anxiety. However, making healthy lifestyle decisions will help reduce the tension. Healthy lifestyle decisions improve a person's tolerance to stress and vice versa. This may understand why the effect of lifestyle decisions on distress levels is much greater than the impact of work results on distress.

The same is true for task overloading. Wearing too many hats at home (e.g., employee, parent, spouse, daughter/son) can be stressful, adding to one's anxiety rather than affecting work results. In addition, a previous study discovered that enhanced job demands and pressure contribute to anger, dissatisfaction, and stress. Similarly, operational discomfort greatly affects both anxiety and workplace satisfaction (Kumar et al., 2021).

\section{Home-based teleworking will potentially affect employee's job performance}

Kumar et al. (2021) found that increased family distractions would increase anxiety and have a harmful effect on work performance. The veil between personal and professional lives vanished during the lockdown when an employee was forced to operate from home without the assistance of house help, classrooms, or day-care facilities. Thus, the person suffered from depression, but they were unable to contribute to the job constructively.

This findings in line with Gibbs and partners' research (2021). The researchers uncovered that insufficient communication and networking between co-workers are negatively impact productivity. Though it decreased, productivity didn't affect average output because of longer working hours.

To summarize, as one's anxiety level rises, so does one's work performance, while one's overall life satisfaction suffers. In comparison, if one's job performance improves due to increased work engagement and mission competence, one's life satisfaction would improve (Kumar et al., 2021).

\section{Organizational discomfort as an additional stressor during WFH}

Because of the outbreak of the situation caused by the pandemic COVID-19, workers were required to adjust a large collection of habits to provide a working position in their homes with sufficient facilities for them to work from their homes in a very short period.

As Baruch (2000) pointed out, teleworking is inappropriate for every workplace, and fewer individuals than predicted found it beneficial. Because of the sudden switch from on-site working to working from home, organizations and employees worldwide were taken aback. Since not all companies have the forms and resources to help each employee's telework, workers experienced organizational distress (Vyas \& Butakhieo, 2020).

Workers are believed to be unaware of WFH means and lack the tools needed for this transition, such as software, access to official documentation, and a suitable working environment. They will feel more distressed as a result of this pain, which will have a negative impact on work results. When one's level of depression rises, so does one's work efficiency and one's overall sense of well-being.

The researchers also highlighted that the biggest challenges with teleworking were a lack of interaction/professional contact with colleagues, a lack of help technology tools such as internet or printer, reconciling teleworking with family life/household chores/dedication to children, and 
time management. That being so, if this procedure is to become a viable alternative or the new standard, proper preparation is expected. Perhaps the working balance would be apparent after the pandemic when WFH is no longer a forced order but rather a versatile choice (Vyas \& Butakhieo, 2020).

\section{CONCLUSION}

COVID-19 has dramatically altered the workplace environment. Most organizations have been forced to move from a physical office to a telework setup. This transition and the current pandemic will cause psychological distress, affecting individual employee job productivity. With this primary goal in mind, this article summarized how home-based teleworking during COVID19 has effects on employee stress and job performance.

A literature review revealed that healthy personal decisions, job overload, and organizational discomfort all substantially impact employee anxiety. Employee work performance is harmed by causes such as family distraction, organizational discomfort, and anxiety. As reported in the studies above, increased longer working hours and job obligations cause tension among workers, while disruptions from family members degrade work efficiency. Though good work performance leads to life satisfaction, depression has a major negative impact on it.

Finally, this essay outlined how job performance and anxiety caused by COVID-19 stressors can impair life satisfaction. This opens the door for further research on work-life harmony under telecommute arrangements for as long as the Covid-19 pandemic persists.

\section{Limitations and future studies}

While the article has significant benefits, it is not without limitations. Since direct interaction was not possible for data collection, the authors relied solely on a literature review. On the other hand, describing and analyzing the impact of others will bring more material to the current literature to ensure greater population coverage. Related research to this one can be seen in other areas of the world. Thus, by conducting this research in Indonesia, the researchers will gain a greater understanding of the current work deprivation levels among the Indonesian population as the COVID-19 pandemic continues.

\section{REFERENCES}

Aguilera, A., Lethiais, V., Rallet, A., \& Proulhac, L. (2016). Home-based telework in France: Characteristics, barriers and perspectives. Transportation Research Part A: Policy and Practice, 92(October), 1-11. https://doi.org/10.1016/j.tra.2016.06.021.

Baruch, Y. (2000). Teleworking: benefits and pitfalls as perceived by professionals and managers. New Technology, Work and Employment, 15(1), 34-49.

Benton, M., Batalova, J., Davidoff-Gore, S., \& Schmidt, T. (2021). COVID-19 and the state of global mobility in 2020. Retrieved from www.migrationpolicy.org.

De', R., Pandey, N., \& Pal, A. (2020). Impact of digital surge during Covid-19 pandemic: A viewpoint on research and practice. International Journal of Information Management, 55(June), 102171. https://doi.org/10.1016/j.ijinfomgt.2020.102171.

Dima, A. M., Tuclea, C. E., Vrânceanu, D. M., \& Tigu, G. (2019). Sustainable social and individual implications of telework: A new insight into the Romanian labor market. Sustainability (Switzerland), 11(3506), 1-12. https://doi.org/10.3390/su11133506.

Fonner, K. L., \& Roloff, M. E. (2010). Why teleworkers are more satisfied with their jobs than are office-based workers: When less contact is beneficial. Journal of Applied Communication Research, 38(4), 336-361. https://doi.org/10.1080/00909882.2010.513998.

Gajendran, R. S., \& Harrison, D. A. (2007). The good, the bad, and the unknown about 
telecommuting: Meta-analysis of psychological mediators and individual consequences. Journal of Applied Psychology, 92(6), 1524-1541. https://doi.org/10.1037/00219010.92.6.1524.

Gautam, R., \& Sharma, M. (2020). 2019-nCoV pandemic: A disruptive and stressful atmosphere for Indian academic fraternity. Brain, Behavior, and Immunity, 88, 948-949. https://doi.org/10.1016/j.bbi.2020.04.025.

Gibbs, M., Mengel, F., \& Siemroth, C. (2021). Work from home \& productivity: Evidence from personnel \& analytics data on IT professionals (No. 2021-56). SSRN Electronic Journal. Chicago. https://doi.org/10.2139/ssrn.3843197.

Hatayama, M., Viollaz, M., \& Winkler, H. (2020). Jobs' amenability to Working from Home: Evidence from skills surveys for 53 countries (No. 9241). Washington DC. Retrieved from http://www.worldbank.org/prwp.

Hegele, C., \& Singh, A. (2020). Balancing work and life under one roof. Retrieved from https://insights.office.com/workplace-analytics/balancing-work-and-life-under-one-roof/.

Illegems, V., Verbeke, A., \& S'Jegers, R. (2001). The organizational context of teleworking implementation. Technological Forecasting and Social Change, 68(3), 275-291. https://doi.org/10.1016/S0040-1625(00)00105-0.

Institute for Public Policy Research. (2020). Covid-19: One in five healthcare workers could quit after pandemic unless urgent government action is taken, IPPR warns. Retrieved from https://www.ippr.org/news-and-media/press-releases/covid-19-one-in-five-healthcareworkers-could-quit-after-pandemic-unless-urgent-government-action-is-taken-ipprwarns.

International Labour Organization. (2020a). An employers' guide on working from home in response to the outbreak of COVID-19. International Labour Organization. Geneva: International Labour Organization. Retrieved from https://www.ilo.org/actemp/publications/WCMS_745024/lang--en/index.htm.

International Labour Organization. (2020b). Teleworking during the COVID-19 pandemic and beyond: A practical guide. Gen: International Labour Organization. Retrieved from www.ilo.org/publns.

Kumar, P., Kumar, N., Aggarwal, P., \& Yeap, J. A. L. (2021). Working in lockdown: The relationship between COVID-19 induced work stressors, job performance, distress, and life satisfaction. Current Psychology. https://doi.org/10.1007/s12144-021-01567-0.

Kurland, N. B., \& Bailey, D. E. (1999). Telework: The advantages and challenges of working here, there, anywhere, and anytime. Organizational Dynamics, 28(2), 53-68.

Loia, F., \& Adinolfi, P. (2021). Teleworking as an eco-innovation for sustainable development: Assessing collective perceptions during COVID-19. Sustainability, 13(4823), 1-16. https://doi.org/10.3390/su13094823.

Madero Gómez, S., Ortiz Mendoza, O. E., Ramírez, J., \& Olivas-Luján, M. R. (2020). Stress and myths related to the COVID-19 pandemic's effects on remote work. Management Research, 18(4), 401-420. https://doi.org/10.1108/MRJIAM-06-2020-1065.

Mazza, C., Ricci, E., Biondi, S., Colasanti, M., Ferracuti, S., Napoli, C., \& Roma, P. (2020). A nationwide survey of psychological distress among Italian people during the Covid-19 pandemic: Immediate psychological responses and associated factors. International Journal of Environmental Research and Public Health, 17(9), 3165. https://doi.org/10.3390/ijerph17093165.

Nemteanu, M. S., \& Dabija, D. C. (2021). The influence of internal marketing and job satisfaction on task performance and counterproductive work behavior in an emerging marketing during the covid-19 pandemic. International Journal of Environmental Research and Public Health, 18(3670), 1-16. https://doi.org/10.3390/ijerph18073670.

Padma, V., Anand, N. N., Gurukul, S. M. G. S., Javid, S. M. A. S. M., Prasad, A., \& Arun, S. (2015). Health problems and stress in Information Technology and Business Process 
Outsourcing employees. Journal of Pharmacy and Bioallied Sciences, 7(April), S9-S13. https://doi.org/10.4103/0975-7406.155764.

Riccobono, F. (2020). Pandemic burnout: $60 \%$ of professionals are working more hours. Retrieved from https://www.teamblind.com/blog/index.php/2020/10/19/pandemic-burnout-60-ofprofessionals-are-working-more-hours/.

Tavares, F., Santos, E., Diogo, A., \& Ratten, V. (2020). Teleworking in Portuguese communities during the COVID-19 pandemic. Journal of Enterprising Communities: People and Places in the Global Economy. https://doi.org/10.1108/JEC-06-2020-0113.

Thorstensson, E. (2020). The influence of working from home on employees' productivity: Comparative document analysis between the years 2000 and 2019-2020. Karistad University, Karlstad. Retrieved from https://www.divaportal.org/smash/get/diva2:1446903/FULLTEXT01.pdf.

Uford, I. C. (2021). Teleworking and stress factor amidst COVID-19 pandemic in total Nigeria. Journal of Marketing Management and Consumer Behavior, 3(2), 48-72.

Vyas, L., \& Butakhieo, N. (2020). The impact of working from home during COVID-19 on work and life domains: An exploratory study on Hong Kong. Policy Design and Practice, 4(1), 59-76. https://doi.org/10.1080/25741292.2020.1863560.

Wang, C., Horby, P. W., Hayden, F. G., \& Gao, G. F. (2020). A novel coronavirus outbreak of global health concern. The Lancet, 395(10223), 470-473. https://doi.org/10.1016/S01406736(20)30185-9.

World Health Organization. (2020). COVID-19 disrupting mental health services in most countries, WHO survey. Retrieved from https://www.who.int/news/item/05-10-2020covid-19-disrupting-mental-health-services-in-most-countries-who-survey. 